\title{
IMPROVEMENT OF CYCLIC FATIGUE LIFE OF TEE WELDED JOINTS BY HIGH-FREQUENCY MECHANICAL PEENING UNDER THE CONDITIONS OF HIGHER HUMIDITY AND TEMPERATURE
}

\author{
V.V. KNYSH, S.A. SOLOVEJ, L.I. NYRKOVA, L.G. SHITOVA and A.A. RYBAKOV \\ E.O. Paton Electric Welding Institute, NASU \\ 11 Kazimir Malevich Str., 03680, Kiev, Ukraine. E-mail: office@paton.kiev.ua
}

\begin{abstract}
The study provides experimental evidence of effectiveness of application of high-frequency mechanical peening (HFMP) to improve the fatigue resistance characteristics of tee welded joints in metal structures, which operate under moderate climatic conditions. Corrosion damage characteristic for such structures after long-term service was achieved by soaking the welded joint in G4 humidity chamber at increased humidity and temperature for $1200 \mathrm{~h}$. Metallographic studies were performed of the weld zone and HAZ in as-welded (unstrengthened) and HFMP-strengthened states before and after corrosive medium impact. It is established that as a result of HFMP strengthening, the joint resistance to the impact of higher humidity and temperature becomes higher. Fatigue tests of welded joints in the initial and strengthened states before and after soaking in the humidity chamber were performed. It is found that strengthening by HFMP technology before the corrosive impact allows increasing the limited endurance limit, based on $2 \cdot 10^{6}$ cycles, of tee welded joints by $48 \%$ and increasing the cyclic fatigue life $6-8$ times. 12 Ref., 1 Table, 7 Figures.
\end{abstract}

Keywords: tee welded joint, corrosive medium, fatigue, high-frequency mechanical peening, ultrasonic impact treatment, improvement of corrosion fatigue resistance

Engineering metal structures in long-term service can be exposed to simultaneous impact of external alternating loading and corrosive media. The service life of such structures is determined by corrosion fatigue resistance of their most loaded joints and components. In order to improve fatigue resistance characteristics of structural components and elements, various methods of surface plastic deformation (SPD) of metal are widely used in practice. Review of the main SPD methods is given in [1].

Over the recent years, investigations have been actively pursued to establish the effectiveness of SPD application to improve the characteristics of corrosion fatigue and corrosion resistance of metals and their welded joints [2-12]. Some works on these subjects are devoted to effectiveness of application of such SPD method, as high-frequency mechanical peening (HFMP) [3, 7, 9, 11, 12] (known in foreign publications as ultrasonic impact treatment). So, in [9] it was shown that depending on technological parameters of HFMP performance, corrosion resistance of strengthened surface layer of the material, determined by corrosion potential, can both increase, or decrease relative to base material. Experimental studies of corrosion fatigue of low-alloyed steel welded joints in $\mathrm{NaCl}$ solution demonstrated that strengthening by HFMP technology allows essentially increasing their cyclic fatigue life [3, 7, 11]. Study [12] shows the good prospects for application of combined strengthening of welded joints by electrospark alloying and HFMP to improve their fatigue corrosion resistance, compared to strengthening just by HFMP. Note that in these studies the time of specimen soaking in corrosive medium was from 10 up to $200 \mathrm{~h}$ during corrosion fatigue testing. At such a time of specimen staying in corrosive medium, no essential corrosion damage of HFMP-strengthened metal layer usually takes place, that may lead to obtaining overestimated characteristics of corrosion fatigue resistance of welded joints, required for design of structures for long-term operation. Corrosion damage, characteristic for metal structures in service, can be produced by pre-soaking the welded joints in corrosive media.

The objective of this work is assessment of effectiveness of HFMP technology application to improve fatigue resistance characteristics of tee welded joints at the stage of manufacturing the metal structures, long-term operation of which will proceed under the conditions of higher humidity and temperature.

Material and investigation procedure. Experimental studies for corrosion fatigue were performed on specimens of tee welded joints of low-alloyed $15 \mathrm{KhSND}$ steel $\left(\sigma_{\mathrm{y}}=400 \mathrm{MPa}, \sigma_{\mathrm{t}}=565 \mathrm{MPa}\right)$, which is widely applied for fabrication of elements of met- 
al structures in long-term service (for instance, span structures of railway and road bridges), has higher strength, is readily weldable, resistant to atmospheric conditions, and serviceable in the temperature range from -70 up to $45{ }^{\circ} \mathrm{C}$. Chemical composition of $15 \mathrm{KhSND}$ steel is as follows, wt.\%: $0.142 \mathrm{C}$; $0.466 \mathrm{Si} ; 0.63 \mathrm{Mn} ; 0.02 \mathrm{~S} ; 0.013 \mathrm{P} ; 0.31 \mathrm{Ni} ; 0.66 \mathrm{Cr}$; $0.34 \mathrm{Cu}$.

Blanks for welded joint specimens were cut out of hot-rolled sheets of $12 \mathrm{~mm}$ thickness (category 12). Dimensions of blanks for tee joints were $350 \times 70 \mathrm{~mm}$. Tee welded joints were produced by manual arc welding with UONI 13/55 electrodes of transverse stiffeners (also from 15KhSND steel) from two sides of the plate by fillet welds. The root (first layer) was welded by $3 \mathrm{~mm}$ electrodes, the weld (second layer) was formed by $4 \mathrm{~mm}$ electrodes. Figure 1 gives the shape and geometrical dimensions of specimens of tee welded joints. Specimen thickness is due to wide application of $12 \mathrm{~mm}$ thick rolled stock in engineering welded structures, and the test portion width of $50 \mathrm{~mm}$ was selected proceeding from test equipment capacity.

Experimental studies were conducted in servohydraulic machine URS-20 at alternating tension with cycle asymmetry $R_{\sigma}=0$ and $5 \mathrm{~Hz}$ frequency at regular loading. The criterion of test completion was total fracture of specimens or exceeding the test base of $2 \cdot 10^{6}$ stress reversal cycles.

Four series of specimens of tee welded joints were tested:

1st: specimens in as-welded (unstrengthened) state;

2nd: specimens strengthened by HFMP;

3rd: specimens in unstrengthened state after soaking in corrosive medium;

4th: specimens strengthened by HFMP after soaking in corrosive medium.

Welded joint strengthening by HFMP technology was conducted with USTREAT-1.0 unit, in which the compact impact hand tool with piezoceramic transducer is connected to ultrasonic generator of $500 \mathrm{~W}$ output power. At welded joint strengthening by HFMP, surface plastic deformation was applied to a narrow zone of weld metal to HAZ transition (along the fusion line). Single-row four striker head with $3 \mathrm{~mm}$ striker diameter was used as strengthening tool. Speed of HFMP performance at tee joint treatment was equal to $1 \mathrm{~mm} / \mathrm{s}$. Amplitude of impact hand tool waveguide edge oscillations was set to $25 \mu \mathrm{m}$.

To produce prior corrosion damage, welded specimens of third and fourth series were placed into G4 chamber, in which they were soaked for $1200 \mathrm{~h}$ at increased humidity $(95 \%)$ and temperature $\left(40{ }^{\circ} \mathrm{C}\right)$.
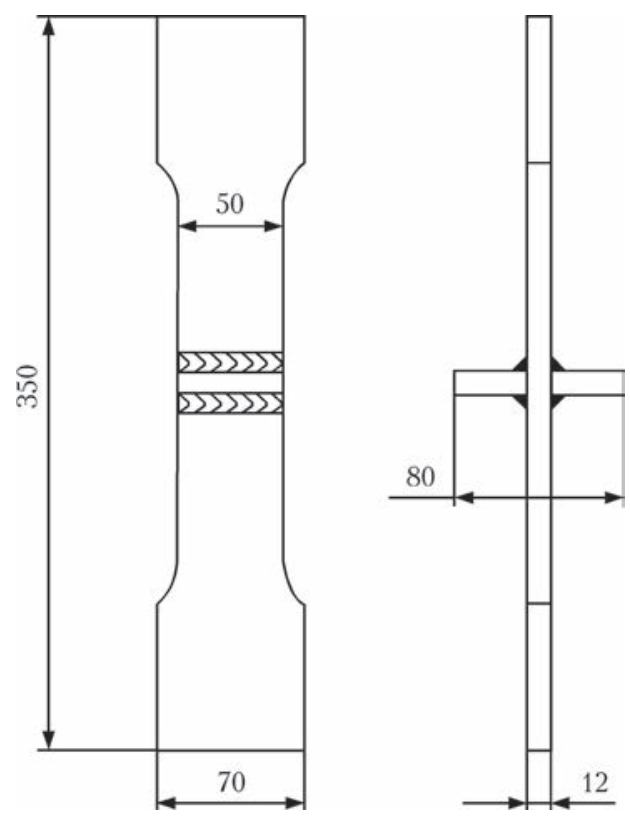

Figure 1. Shape and geometrical dimensions of tee welded joint specimen

Metallographic studies of surface layer of metal of welds and HAZ of tee joints in as-welded (unstrengthened) state and in the state after strengthening by HFMP were performed before and after soaking in the chamber at increased humidity and temperature.

Investigation results. Metallographic studies of base metal and welded joint established the following. Microstructure of base metal of $15 \mathrm{KhSND}$ steel rolled stock is ferritic-pearlitic, with about 30-35\% fraction of pearlitic component, striation of 3-4 points from B range to GOST 5640. Grain size corresponds to \#7-9 of scale 1 to GOST 5639.

Dimensions of welds and HAZ were determined before microstructural studies of welded joints. Fillet weld width was equal to $12.8-14.3 \mathrm{~mm}$, height was 9.5-12.0 mm. Here, the height of the first weld layer was 4.5 to $6.5 \mathrm{~mm}$, that of the second was $6.8-8.3 \mathrm{~mm}$; that of the HAZ was equal to $1.04-2 \mathrm{~mm}$ due to visible changes in metal structure in rolled stock surface layers, and in metal layers farther from the surface it was 3.0-3.8 mm.

Microstructure of the first metal layer was a cellular ferritic-pearlitic structure with grain size \#6-8 to GOST 5639 scale 1. Ferrite grains with fine precipitates of MAC-phase of granular type and precipitate-free grains were also detected. Pearlite formations have the form of narrow regions along ferrite grain boundaries. Microstructure of the second layer of weld metal has sufficiently uniform dendritic ferritic-pearlitic structure. Ferrite component contains grains with plate-like MAC-phase precipitates of the type of upper bainite, fine particles of grain type (of lower bainite type), as well as grains of quite large acicular ferrite. 


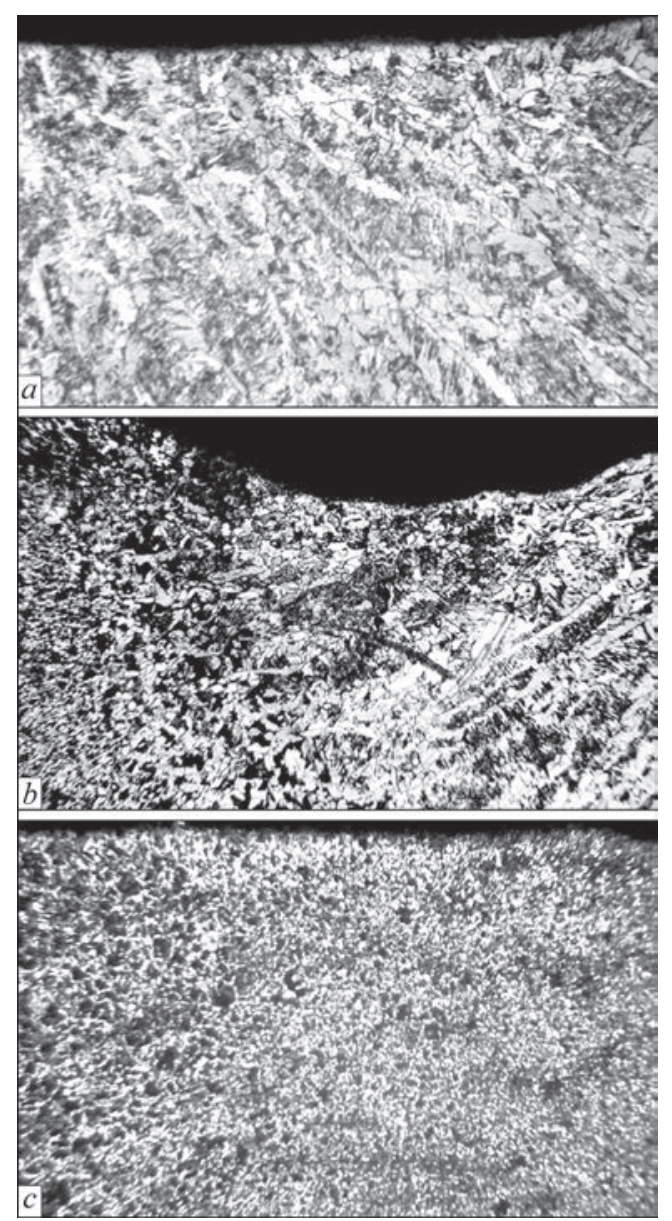

Figure 2. Microstructure $(\times 100)$ of surface layer of weld $(a)$, CGZ (b) and HAZ (c) metal of tee welded joint in as-welded state

HAZ metal microstructure is as follows. Immediately at the surface, grain size of coarse-grain zone (CGZ) corresponds to \#3-4 to GOST 5639, and its extent is $0.52 \mathrm{~mm}(2-3$ grains $)$. At about $3 \mathrm{~mm}$ dis-

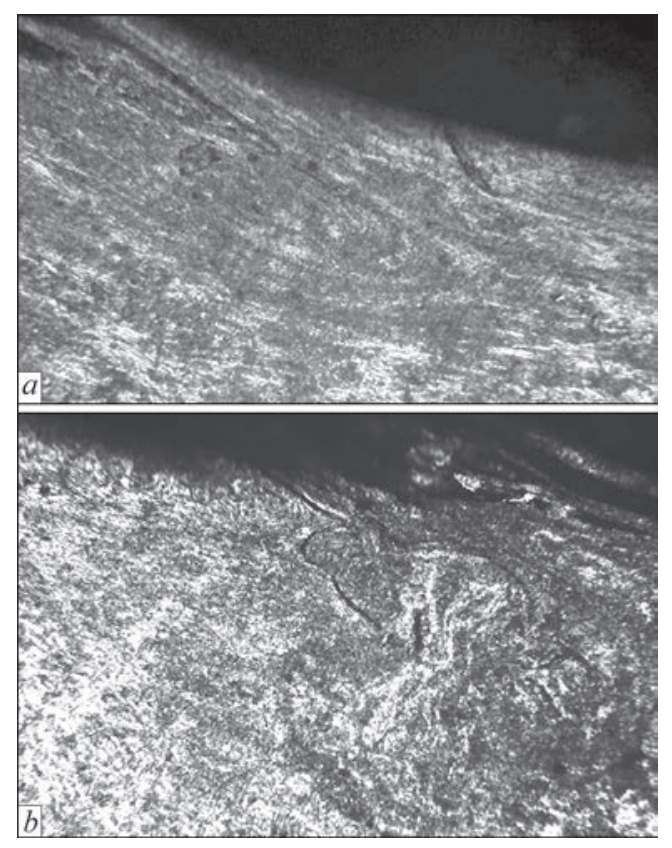

Figure 3. Microstructure $(\times 250)$ of weld $(a)$ and HAZ $(b)$ metal after strengthening by HFMP technology tance from the surface, CGZ size increases up to $1.04-1.20 \mathrm{~mm}$, but grain size remains on the level of \#3-4. Size of pearlite-ferrite grains in fine-grain zone, the size of which is about $1 \mathrm{~mm}$, is equal to \#7-10. In CGZ metal of first weld, mainly a mixture of \#5-8 ferrite-pearlite grains of up to $0.91 \mathrm{~mm}$ length was formed. CGZ structure in the second weld consists of ferrite with densely distributed in its matrix MACphase precipitates, with chaotic dispersed particles of grain type, less often - with ordered plate-like particles (of lower or upper bainite type). Grains demonstrate fragmentation - grain division into individual fragments with MAC-phase of different morphology and orientation. Grain boundaries are fringed with ferrite in the form of 1-3 $\mu \mathrm{m}$ wide interlayers and sequences of elongated \#8-9 grains. Hardness of first weld metal layer is in the range of $H V 0.98-232-241$, that of the second one is HV0.98-292-325. Microstructure of surface layer of weld metal, CGZ metal and HAZ metal of tee welded joint in as-welded state is given in Figure 2.

After HFMP, characteristic grooves of practically the same size formed on the line of weld fusion with base metal in the surface layers of the metal of welds and HAZ. Groove width is in the range of $3.0-3.5 \mathrm{~mm}$, their depth being 280-340 $\mu \mathrm{m}$. Plastically deformed layers of weld metal of 1.70-1.82 mm width and HAZ metal of 1.3-1.7 mm width formed under the groove. Depth of plastically deformed layer of weld and HAZ metal, due to visible changes of metal structure under the groove, was equal to $390-650 \mu \mathrm{m}$.

HFMP essentially changed the cast structure of weld metal (Figure 3,a). Elongated bainite grains, with grain shape coefficients $K_{\mathrm{sh}}=5-17\left(K_{\mathrm{sh}}=a / b\right.$, where $a$ and $b$ are the length and width of elongated grain, respectively), which are practically parallel to groove bottom, and thread-like ferrite veins formed in the surface layer of metal of up to $130 \mu \mathrm{m}$ depth. Ferrite grains with $K_{\mathrm{sh}}=4-7$ and individual baintie grains are observed at $260 \mu \mathrm{m}$ distance from groove bottom.

Changes of grain structure of HAZ metal were also found (Figure 3, $b$ ). Bainite and ferrite grains elongated at an angle to groove bottom, with $K_{\mathrm{sh}}=7-15$, form in CGZ surface layers of up to $280 \mu \mathrm{m}$ depth. With further distance from groove bottom, fine ferrite-pearlite grains of \#9-11 are observed also in finegrain zone. Several delaminations of 40 to $300 \mu \mathrm{m}$ length were found in strengthened metal layer.

Measurements of microhardness were performed in plastically deformed metal layer. Owing to an essential increase of the level of dislocation density as a result of HFMP, microhardness of strengthened metal layer $(H V 0.2-344-445)$ is by $27 \%$ higher than that of CGZ and by $35 \%$ higher than that of weld metal. 


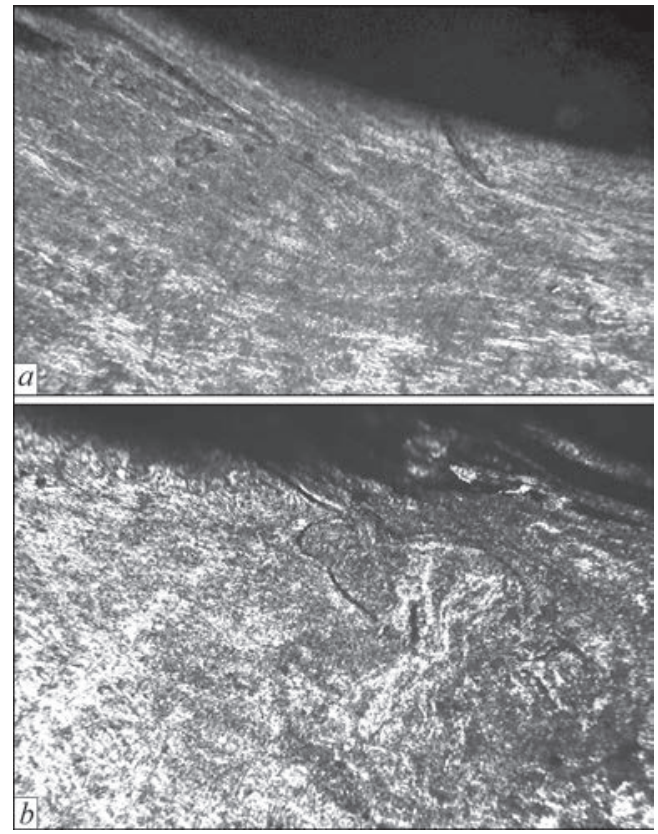

Figure 4. Corrosion damage in HAZ metal of tee welded joint in unstrengthened state after testing at increased humidity and temperature: $a-\times 100 ; b-\times 250$

In surface layers of metal of weld and HAZ in as-welded (unstrengthened) state quite deep and extended corrosion damage in the form of spots of up to $2.80 \times 0.26 \mathrm{~mm}$ size, and sometimes in the form of cavities of up to $1.56 \times 1.17 \mathrm{~mm}$ size, is observed after soaking in G4 chamber at higher humidity and temperature (Figure 4). In surface layers of fillet weld metal and HAZ, plastically deformed by HFMP, similar types of corrosion were found (Figure 5, a,b) after soaking in G4 chamber, their maximum size not exceeding $1.95 \times 0.16 \mathrm{~mm}$. Moreover, the strengthened layer of weld metal demonstrates corrosion in the form of acicular intercrystalline cracks with corrosion products of $0.65-1 \mathrm{~mm}$ length and up to $0.65 \mathrm{~mm}$ depth (Figure 5,c).

The Table gives the results of metallographic investigations with calculated values of the extent of damage and total dimensions of damage area projections, depth of corrosion spot and cavity penetration into the surface layers of metal of fillet welds and HAZ. Depth of cavity penetration into HAZ metal surface layer is not more than 0.39 and $0.26 \mathrm{~mm}$ for welded joints in as-welded and HFMP-strengthened states, respectively. Corrosion cavities in surface layers of weld metal both in as-welded state and in HFMP-strengthened state are deeper and reach $1.17 \mathrm{~mm}$. This is, apparently, related to specifics of forming the second weld layer in manual arc welding. On the whole, specimens of tee welded joints, strengthened by HFMP technology, have higher resistance to the impact of higher humidity and temperature (see the Table).

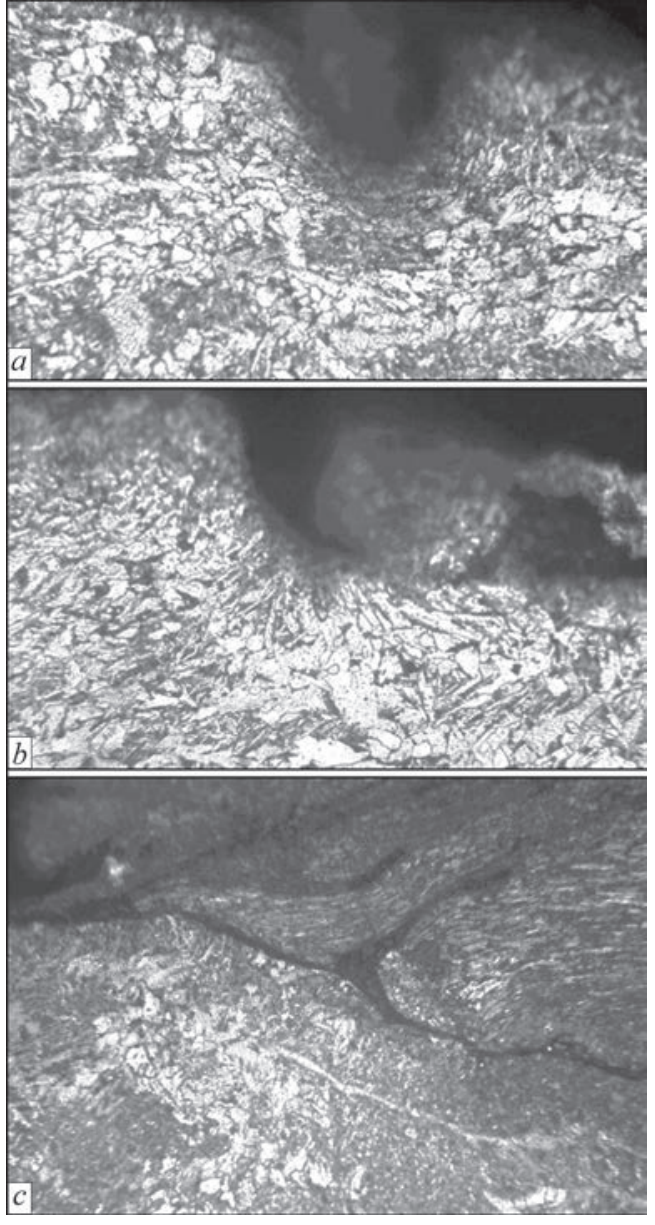

Figure 5. Corrosion damage in the form of spots $(a, b)$ and cracks $(c)$ in surface layer of metal of tee welded joint strengthened by HFMP, after testing under the conditions of increased humidity and temperature: $a-\times 100 ; b, c-\times 250$

$\sigma, \mathrm{MPa}$

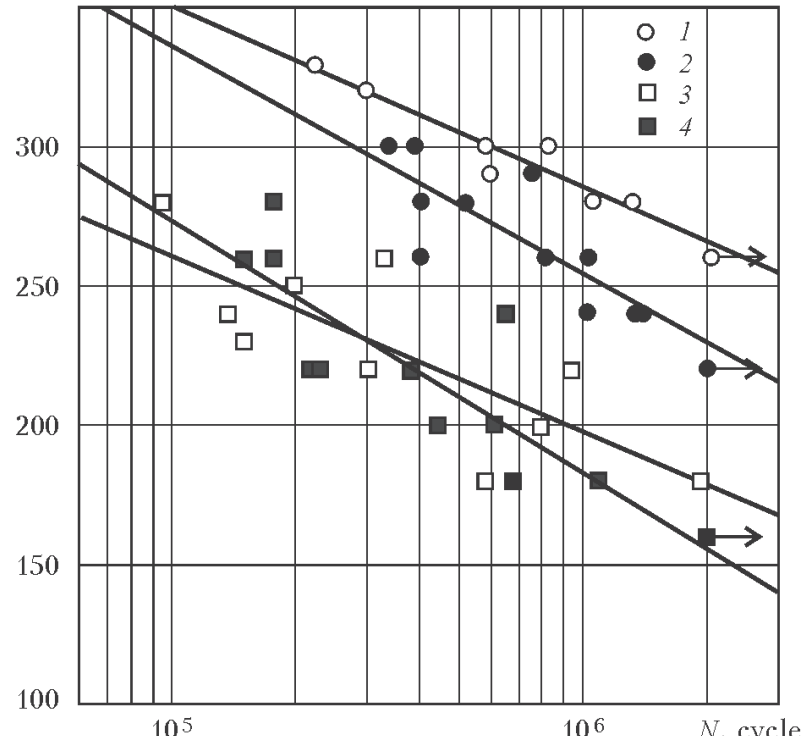

Figure 6. Fatigue curves of tee welded joints of $15 \mathrm{KhSND}$ steel: 1, 2 - in HFMP-strengthened state; 3, 4 - in as-welded (unstrengthened) state, before and after soaking in G4 humidity chamber for $1200 \mathrm{~h}$, respectively 
Dimensions of corrosion damage in surface layers of metal of welds and HAZ of tee welded joints of $15 \mathrm{KhSND}$ steel after soaking for $1200 \mathrm{~h}$ at increased humidity and temperature

\begin{tabular}{|c|c|c|c|c|c|c|}
\hline \multirow[b]{2}{*}{ Specimen state } & \multicolumn{3}{|c|}{ Spot corrosion of weld surface layers } & \multicolumn{3}{|c|}{ Spot corrosion of HAZ surface layers } \\
\hline & $\begin{array}{c}\text { Extent } \\
\text { of damage, \% }\end{array}$ & $\begin{array}{c}\text { Depth } \\
\text { of damage, } \mathrm{mm}\end{array}$ & $\begin{array}{c}\text { Total } \\
\text { projection } \\
\text { of damage } \\
\text { area, } \mathrm{mm}\end{array}$ & $\begin{array}{c}\text { Extent } \\
\text { of damage, \% }\end{array}$ & $\begin{array}{c}\text { Depth } \\
\text { of damage, } \mathrm{mm}\end{array}$ & $\begin{array}{c}\text { Total } \\
\text { projection } \\
\text { of damage } \\
\text { area, } \mathrm{mm}\end{array}$ \\
\hline Unstrengthened & 31.2 & $0.091-1.17$ & 17.615 & 38.5 & $0.13-0.39$ & 5.85 \\
\hline HFMP-strengthened & 23 & $0.13-1.17$ & 12.44 & 29 & $0.13-0.26$ & 4.42 \\
\hline
\end{tabular}

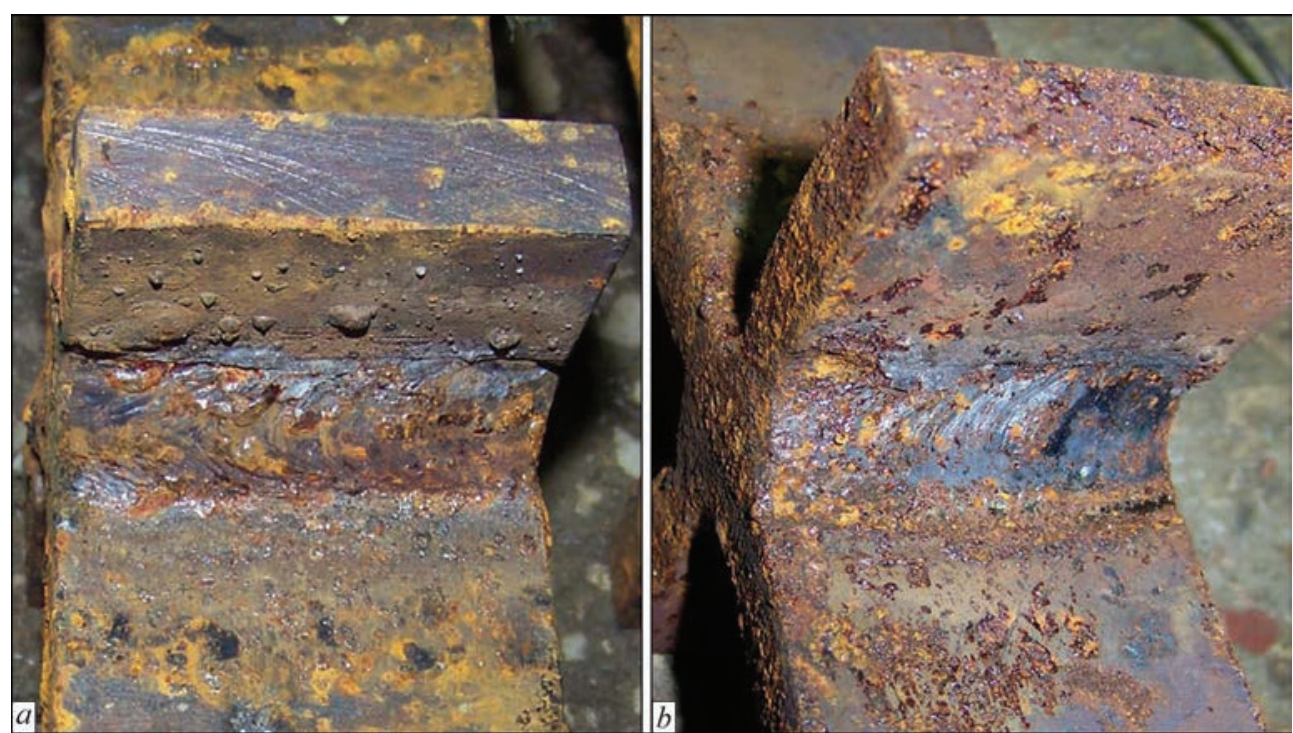

Figure 7. Appearance of weld zone in as-welded $(a)$ and HFPM-strengthened $(b)$ state after soaking for $1200 \mathrm{~h}$ at increased humidity and temperature

Results of fatigue testing of all four series of specimens are given in Figure 6, and the appearance of weld zone in as-welded and HFMP-strengthened states after soaking in humidity chamber for $1200 \mathrm{~h}$ is shown in Figure 7.

The given fatigue curves ( 1 and 3, see Figure 6) demonstrate that application of HFMP technology as a method of SPD of the metal of joints near the areas of fatigue damage accumulation essentially improves fatigue resistance characteristics of tee welded joints without corrosion damage. Cyclic fatigue life of joints rises more than 20 times, and limited endurance limit on the base of $2 \cdot 10^{6}$ cycles is increased by approximately $47 \%$ (from 180 to $265 \mathrm{MPa}$ ). Soaking of tee welded joint specimens in the chamber at higher humidity and temperature for $1200 \mathrm{~h}$ leads to lowering of limited endurance limits on the base of $2 \cdot 10^{6}$ cycles of unstrengthened welded joints by approximately $14 \%$ (from 180 to $155 \mathrm{MPa}$ ), and in those strengthened by HFMP — by approximately $13 \%$ (from 265 to $230 \mathrm{MPa}$ ). Results obtained on welded joints after corrosive impact (curves 2 and 4 ) show that prior strengthening by HFMP increases the limited endurance limit of such joints by approximately $48 \%$ (from 155 to $230 \mathrm{MPa}$ ), while cyclic fatigue life rises by 6-8 times. Fracture of HFMP-strengthened welded joints, tested both before and after soaking in G4 humidity chamber, ran mainly at a distance from the weld and HAZ.

Thus, experimental results are indicative of high effectiveness of HFMP technology application to improve fatigue resistance characteristics of tee welded joints in metal structures, operating under moderate climatic conditions under the impact of alternating loading (curves 2 and 4, see Figure 6). Here, it should be noted that protection of HFMP-strengthened surface metal layer from direct impact of atmospheric conditions, i.e. from corrosion damage (for instance, due to application of lacquer-paint coatings), allows achieving maximum characteristics of fatigue resistance of such joints (see curve 1 ).

\section{Conclusions}

1. Metallographic investigations were performed of surface layers of metal of weld and HAZ in as-welded (unstrengthened) and HFMP-strengthened states before and after corrosive medium impact. Proceeding from calculations of the extent and depth, as well as total size of projection of the area of damage by corrosion spots and cavities in surface layers of metal of fillet welds and HAZ of tee welded joints, it was established that strengthening by HFMP technology 
improves joint resistance to the impact of higher humidity and temperature.

2. It was confirmed that strengthening by HFMP essentially improves the fatigue resistance characteristics of low-alloy steel welded joints in air. Cyclic fatigue life of tee welded joints of 15KhSND steel after strengthening rises by more than 20 times, and limited endurance limit on the base of $2 \cdot 10^{6}$ cycles increases by $47 \%$.

3. High effectiveness of HFMP application to improve fatigue resistance characteristics of welded joints of metal structures, operating under moderate climatic conditions, was established. Strengthening of tee welded joints of $15 \mathrm{KhSND}$ steel before soaking in higher humidity and temperature chamber for $1200 \mathrm{~h}$ leads to 6-8 times increase of cyclic fatigue life, depending on levels of applied stresses, and $48 \%$ increase of limited endurance limit on the base of $2 \cdot 10^{6}$ cycles.

1. Kulekci, M.K., Esme, U. (2014) Critical analysis of processes and apparatus for industrial surface peening technologies. Int. J. Advanced Manufact. Techn., 74(9), 1551-1565.

2. Pokhmursky, V.I., Khoma, M.S. (2008) Corrosion fatigue of metals and alloys. Lviv: SPOLOM.

3. Kolomijtsev, E.V., Serenko, A.N. (1990) Effect of ultrasonic and laser treatment on fatigue resistance of butt welded joints in air and corrosion media. Avtomatich. Svarka, 11, 13-15.
4. Nasilowska, B., Bogdanowicz, Z., Wojucki, M. (2015) Shot peening effect on $904 \mathrm{~L}$ welds corrosion resistance. J. Constr. Steel Res., Vol. 115, 276-282.

5. Ahmed, A.A., Mhaede, M., Wollmann, M. et al. (2014) Effect of surface and bulk plastic deformations on the corrosion resistance and corrosion fatigue performance of AISI 316L steel. Surface \& Coating Techn., Vol. 259, 448-455.

6. Lee Hang-sang, Kim Doo-soo, Jung June-sung et al. (2009) Influence of peening on the corrosion properties of AISI 304 stainless steel. Corrosion Sci., Vol. 51, 2826-2830.

7. Knysh, V.V., Valteris, I.I., Kuzmenko, A.Z. et al. (2008) Corrosion fatigue resistance of welded joints strengthened by high-frequency mechanical peening. The Paton Welding $J$, 4, 2-4.

8. Kolomijtsev, E.V. (2012) Corrosion-fatigue strength of 12Kh18N10T steel T-joints and methods of its improvement. Ibid., 12, 36-38.

9. Mordyuk, B.N., Prokopenko, G.I., Vasylyev, M.A. et al. (2007) Effect of structure evolution induced by ultrasonic peening on the corrosion behavior of AISI-321 stainless steel. Mater. Sci. and Eng. A, Vol. 458, 253-261.

10. Hashemi, B., Rezaee Yazdi, M., Azar, V. (2011) The wear and corrosion resistance of shot-peened nitrided $316 \mathrm{~L}$ austenitic stainless steel. Materials and Design, 32, 3287-3292.

11. Daavary, M., Sadough Vanini, S.A. (2015) Corrosion fatigue enhancement of welded steel pipes by ultrasonic impact treatment. Mater. Lett., Vol. 139, 462-466.

12. Prokopenko, G.I., Mordyuk, B.N., Knysh, V.V. et al. (2014) Improvement of fatigue and corrosion resistance of welded joints by ultrasonic impact treatment and electrical-discharge alloying. Tekhn. Diagnostika i Nerazrush. Kontrol, 3, 34-40.

Received 02.02.2016 